\title{
Interaction of Arachidonic Acid with Electrogenic Properties of Mouse Chemosensory Neurons
}

\author{
A. Mazzatenta ${ }^{1}$, C. Di Giulio ${ }^{1}$, M. Pokorski ${ }^{2}$ \\ ${ }^{1}$ Department of Neuroscience and Imaging, University Chieti-Pescara 'G. d'Annunzio', Italy; ${ }^{2}$ Department of Respiratory Research, \\ Medical Research Center, Polish Academy of Sciences, Warsaw, Poland
}

\begin{abstract}
Chemosensory neurons respond to stimulation induced by gasses, volatile and non-volatile compounds. Neuronal excitation mediated via second messengers involves typically: cGMP, cAMP, or $\mathrm{IP}_{3}$. Transduction pathways based on cyclic nucleotide have three-phosphate nucleotide as substrate, while $\mathrm{IP}_{3}$ has a membrane lipid substrate. These derivatives of cholesterol are signaling molecules with modulator-like effects on many proteins, including membrane ion channels. In the present study, spontaneous and induced activities were recorded in a whole-cell configuration, in current and voltage clamp modes, in isolated chemosensory neurons obtained from the mouse. Chemosensory neurons responded with an inward depolarizing current to application of arachidonic acid, which suggests a role for it in putative mechanisms of signal transduction.
\end{abstract}

Key words: chemosensory neuron, PUFAs, arachidonic acid, transduction mechanisms, current clamp, voltage clamp

\section{INTRODUCTION}

An association between lung function and chemosensory activity has been demonstrated [1]. Chemosensory neurons respond to stimulation induced by a wide range of chemical agents, ranging from gasses $\left(\mathrm{CO}_{2}\right.$, $\mathrm{NO}$ ), volatile (odorants, steroid derivates), and nonvolatile compounds (hormones, neurotransmitters). Neuronal excitation involve typically second messengers such as cGMP, cAMP and inositol-1,4,5-trisphosphate $\left(\mathrm{IP}_{3}\right)$. Furthermore, important transduction pathways are based on the polyunsaturated fatty acids (PUFAs) components of the neuronal plasma membrane phospholipids. PUFAs behave as signaling molecules with modulator effects on many proteins, including membrane ion channels [2-4]. Membrane-bound PUFAs modulate membrane fluidity as well as the functional properties of membrane proteins $[5,6]$. In particular, arachidonic acid (AA), a 20-carbon PUFA, is normally found esterified to cell membrane glycerophospholipids. In response to many a first messenger, including neurotransmitters, AA can be released from these cellular pools by phospholipases and can act as a precursor to several biologically active com- pounds $[3,7]$. The three major enzymatic ways for AA oxidation are the cyclooxygenase, lipooxygenase, and cytochrome P450 monooxygenase pathways [8-10]. In the cyclooxygenase pathway, PGH synthases generate $\mathrm{PGH}_{2}$, which can be further metabolized to other PG, thromboxane, and prostacyclin. Lipooxygenases generate HPETEs, which are converted to leukotrienes and dienols (HETEs). Cytochrome P450 monooxygenases generate four regioisomeric epoxyeicosatrienoic acids (5,6-, 8,9-, 11,12- and 14,15-EET), several midchain cis,trans-conjugated HETEs, and alcohols of AA (19-OH-AA and 20-OH-AA) [8-10]. EETs are further metabolized by epoxide hydrolases to four regioisomeric dihydroxyeicosatrienoic acids (5,6-, 8,9-, 11,12- and 14,15-DHETs) [11]. Both EETs and DHETs have been shown to influence a variety of biological processes, including control of vascular [12, 13] and airway [14] smooth muscle tone, regulation of pituitary/hypothalamic and pancreatic peptide hormone release [15-17], inhibition of platelet aggregation [18], and modulation of fluid and electrolyte transport [19]. These compounds are dietary essential omega-3 fatty acid and possess both cardio- and neuroprotective properties $[20,21]$.

AA levels increase during inflammation and it behaves as an inflammatory mediator [22]. Furthermore, proinflammatory mediators, such as bradykinin [23] and the cytokine tumor necrosis factor alpha (TNF- $\alpha$ ) $[24,25]$ can increase AA synthesis by activating cytosolic $\mathrm{PLA}_{2}$. AA epoxygenase metabolites cause significant changes in rat airway electrical parameters and may be involved in the control of lung fluid and electrolyte transport [26]. It has been shown that airway smooth muscle metabolizes AA through various enzymatic pathways, including cytochrome P450 hydroxylase, which leads to the production of HETE [27].

Because lung function is related to chemosensory activity [1], AA could affect several pathophysiological reactions due to pulmonary diseases, such as COPD. The AA cascade is possibly one of the most intricate signaling systems, since it generates multiple messenger molecules that may act both outside and inside of the neuron. In the present study we sought, therefore, to determine whether chemosensory neurons can respond to AA. We addressed the issue using patchclamp methods to study electrophysiological proper- 
ties of the isolated mouse chemosensory neurons in response to AA application.

\section{Material ANd Methods}

All experiments conformed to the international guidelines on the ethical use of animals (86/609/EEC). C57BL isolated mouse chemosensory neurons were used for the study. The neurons were isolated according to standard enzymatic-mechanical dissociation protocols [28]. Dissociated cells were plated onto Petri dishes and stored for stabilization for $1 \mathrm{~h}$. Isolated neurons were then used for experiments up to two hours and constantly perfused with normal Ringer solution (mM: $140 \mathrm{NaCl}, 5 \mathrm{KCl}, 1 \mathrm{CaCl}_{2}, 1 \mathrm{MgCl}_{2}, 10$ $\mathrm{HEPES}_{\mathrm{Na} 0.5}, 1$ sodium pyruvate, $10 \mathrm{D}-(+)$ glucose, $\mathrm{pH}$ 7.4, and osmolality 300-310 mOsm). The intracellular pipette solution contained in $\mathrm{mM}$ : $145 \mathrm{KCl}, 4 \mathrm{MgCl}_{2}$, 10 HEPES $_{\mathrm{Na} 0.5}, 0.5$ EGTA, 1 ATP, 0.1 GTP, pH 7.3, and 310-315 mOsm. Borosilicate pipette have resistance ranging from 2 to $10 \mathrm{M} \Omega$. All chemicals used in this study were obtained from Sigma-Aldrich (St. Louis, MO). $50 \mu \mathrm{M}$ AA or $50 \mathrm{mM} \mathrm{KCl}$ was applied for 2 s using a fast perfusion stepper system [29]. To prevent oxidation, AA was dissolved in DMSO under nitrogen and stored at $-80^{\circ} \mathrm{C}$. To avoid micelle formation, solutions were briefly sonicated and then vortexed. Electrophysiological recordings were made using an Axopatch system (Axon Instruments, CA) in a whole-cell configuration in both current and voltageclamp modes [30]. Currents data were filtered at $5 \mathrm{kHz}$ and digitized at $12 \mathrm{kHz}$. Analysis was performed using Clampfit 9 (Axon Instruments, CA) and Origin (OriginLab, Northampton, MA).

\section{RESULTS}

In the current-clamp mode of the whole-cell configuration, there was spontaneous firing activity recorded in the chemosensory neurons (Fig. 1A) of the peak amplitude and duration of $80 \pm 10 \mathrm{mV}$ and $40 \pm 5 \mathrm{~ms}$, respectively. Current injections of $2-10 \mathrm{pA}$ induced regular neuronal firing activity (Fig. 1B). Moreover, after switching to a voltage-clamp mode, voltage-gated currents were recorded, induced by $10 \mathrm{mV}$ voltage increments from -80 to $+50 \mathrm{mV}$ (Fig. 2). These preliminary protocols were used to establish the healthy state of the patched cells. The chemosensory neurons that turned out electrically sensitive in both current- and voltage-clamp modes, as shown in Fig. 3, were chosen for further experiments.

The control experiment was performed by administration of $50 \mathrm{mM} \mathrm{KCl}$ through fast stepper system to patched isolated neurons (Fig. 4A). An inward current
A

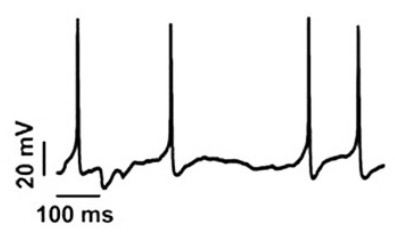

B

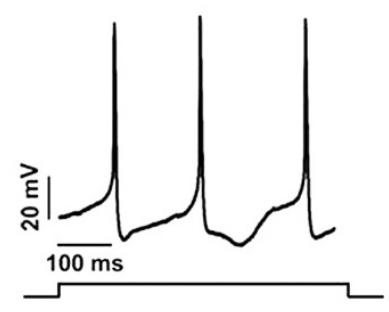

Fig. 1. Typical spontaneous firing activity of an isolated chemosensory neuron recorded in a whole-cell configuration and current-clamp mode Panel A) and induced firing in response to current injections of $2-10 \mathrm{pA}$ for $1 \mathrm{~s}$ recorded in a current clamp mode and whole-cell configuration.

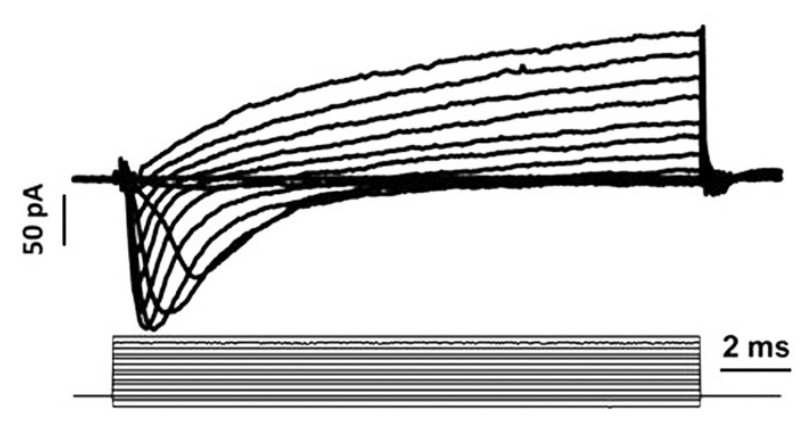

Fig. 2. Representative voltage-gated inward and outward currents elicited by voltage steps, $10 \mathrm{mV}$ increments from -80 to $+50 \mathrm{mV}$ in a whole-cell configuration and voltage clamp mode.

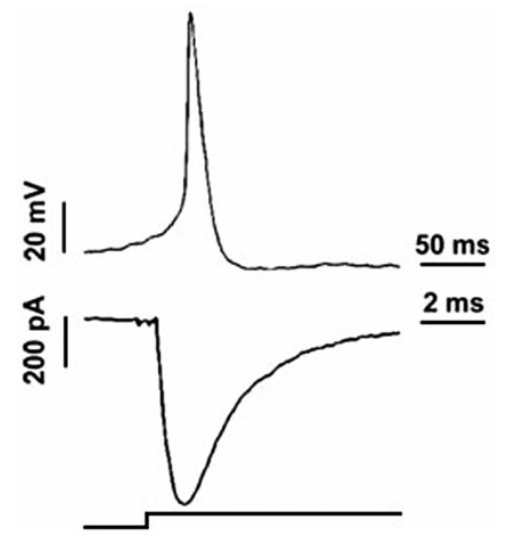

Fig. 3. Comparison of a healthy chemosensory neuron recorded in current and voltage clamp modes; evoked responses.

\section{A}

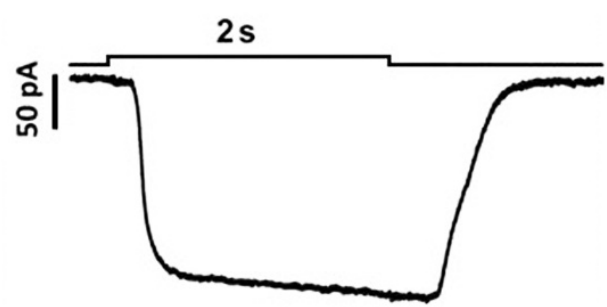

B

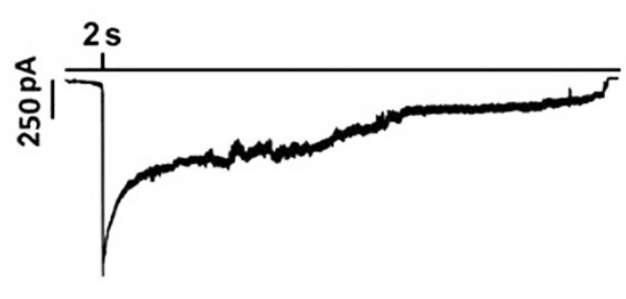

Fig. 4. Representative responses to administration of $50 \mathrm{mM} \mathrm{KCl}$ - control experiment (Panel A) and $50 \mu \mathrm{M}$ AA - arachidonic acid experiment (Panel B). 


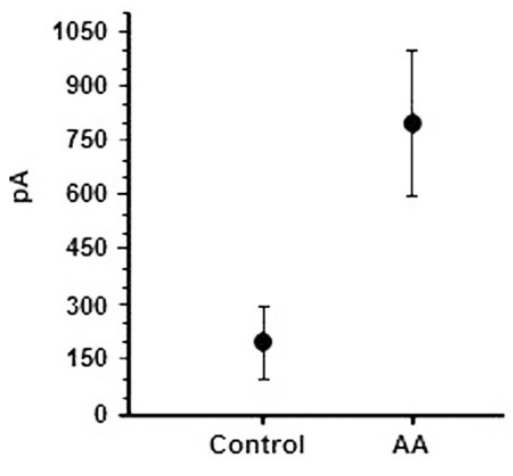

Fig. 5. Mean amplitude of responses to administration of 50 $\mathrm{mM} \mathrm{KCl}$ in control experiments and $50 \mu \mathrm{M} \mathrm{AA}$ in arachidonic acid experiments $(\mathrm{P}<0.01)$.

of the mean amplitude of response of $200 \pm 100 \mathrm{pA}$ in the voltage-clamp mode was recorded. This was a depolarizing current that exhibited a complete recovery after removing the stimulus. The effect of administration of $50 \mu \mathrm{M}$ AA in the voltage-clamp mode is shown in Fig. 4B. AA induced a fast inward depolarizing current of the mean amplitude of $800 \pm 200 \mathrm{pA}$. Complete recovery was typically reached in about 2 min. AA was administered in 15 trials. A paired t-test for the differences between the maximum amplitudes of inward currents elicited by AA vs. control gave a significant result at $\mathrm{P}<0.01$ (Fig. 5).

\section{Discussion}

The purpose of the present study was to investigate whether the chemosensory neurons' electrical activity could be affected by AA. To verify this purpose we performed patch-clamp experiments on isolated mouse chemosensory neurons found to have inherent spontaneous firing activity and to be responsive in a regular incremental way to current injections. The major finding of the study was that AA provoked a depolarization of chemosensory neurons. A regular pattern of neuronal responses, repeatability, and a complete recoverability after the electrical stimulus had ceased acting demonstrate the ability of AA to interact with electrogenic properties of the mouse chemosensory neurons. AA elicits an intricate signaling system as it generates multiple messenger molecules that may act both intra- and extracellularly. The present finding of electrophysiological effects exerted by AA in chemosensory neurons strongly implicates its potential role in signal transduction mechanisms of the cells. The implication is strengthened by other reports showing the effects of AA exerted on sensory neurons [31, 32].

AA is involved in a number of physiological pathways depending on the enzyme that acts on it. Interestingly, AA has been found in abundance in nasal mucosa [33], and the airway smooth muscles metabolize it as well [27]. AA also may be involved in the control of fluid and electrolyte transport in the lung [26]. AA has a short lifespan, during which it may interact with the activity of ion channels and protein kinases within the cell. Alternatively, it may be transformed into a family of metabolites, the eicosanoids, which may also pro- duce separate effects on intracellular targets. In either case, the AA cascade affects neuronal excitability. Furthermore, these compounds can cross the cell membrane, diffuse through the extracellular space, and interact with high-affinity receptors located on neighboring neurons. Therefore, the AA cascade may give rise to both intracellular second messengers and to local mediators, bridging the gap between transmembrane and transcellular communication. This twopronged role may be important in integrating the responses of postsynaptic neurons with the activity of presynaptic terminals and of other contacting cells.

AA modulates directly or indirectly by its metabolites, a wide variety of ion channels [34]. One proposed mechanism of this modulation is through a binding to the ion channel, since the channel modulation depends on the membrane potential $[35,36]$ and mutations of specific residues in the pore region [37]. AA potentiates acid-sensing ion channels (ASICs) in sensory neurons by a direct action [33]. The ASICs family underlies the inward current induced by acidity [38], such as vanilloid receptor activation by AA or its metabolites [39]. Stimulation of cells leads to an increase of $\left[\mathrm{Ca}^{2+}\right]_{\mathrm{i}}$ due to $\mathrm{Ca}^{2+}$ release from intracellular organelles and $\mathrm{Ca}^{2+}$ entry across the plasma membrane. This process is initiated upon the binding of a stimulus-released neurotransmitter to its receptors and activation of phospholipase C (PLC). PLC, in turn, converts phosphatidylinositol-4,5-bisphosphate $\left(\mathrm{PIP}_{2}\right)$ to $\mathrm{IP}_{3}$ and diacylglycerol (DAG). Plasma membrane channels, e.g., TRP channels, are activated and extracellular cations, including $\mathrm{Ca}^{2+}$, flow into the cell. The activation of plasma membrane channels might involve a reduction of $\mathrm{PIP}_{2}$ concentration or an increase in DAG or its metabolites, such as polyunsaturated fatty acids [40].

The finding that chemosensory neurons responded to AA administration with an inward depolarizing current raises the question of a physiological role and the exact determinants of the possible transduction pathway underlain by AA or its metabolites. We could speculate that such a pathway could be specific for a subtype of neurons involved in transduction of chemical stimuli, control of electrolyte transport, or inflammatory conditions. Alternative study designs are required to verify these mechanisms and to attribute a role for AA in signaling pathways.

Acknowledgments: Prof. M. Pokorski was supported by grants from Convenzione tra l'Universita degli Studi “G.d'Annunzio" di Chieti e Pescara and Al Ministero Affari Esteri in Rome.

Conflicts of interest: The authors declared no conflicts of interest in relation to this article.

\section{REFERENCES}

1. Di Giulio C, Data PG, Lahiri S. Chronic cobalt causes hypertrophy of glomus cells in the rat carotid body. Am J Physiol 1991; 261: 102-5.

2. Piomelli D, Greengard P. Lipoxygenase metabolites of arachidonic acid in neuronal signalling. Trends Pharmacol Sci 1990; 11: 367-73.

3. Axelrod J. Receptor-mediated activation of phospholipase $\mathrm{A}_{2}$ and arachidonic acid release in signal transduction. Biochem Soc Trans 1990; 18: 503-7. 
4. Liu Y, Liu D, Heath L, Meyers DM, Krafte DS, Wagoner PK, Silvia CP, Yu W, Curran ME. Direct activation of an inwardly rectifying potassium channel by arachidonic acid. Mol Pharmacol 2001: 59: 1061-8.

5. Stubbs CD, Smith AD. The modification of mammalian membrane polyunsaturated fatty acid composition in relation to membrane fluidity and function. Biochim Biophys Acta 1984; 779: 89-137.

6. Piomelli D. Eicosanoids in synaptic transmission. Crit Rev Neurobiol 1994; 8: 65-83.

7. Baker RR, Chang HY. The hydrolysis of natural phosphatidylethanolamines by phospholipase $A_{2}$ from rat serum: a degree of selectivity is shown for docosahexaenoate release. Biochim Biophys Acta 1992; 1125: 56-61.

8. Capdevila JR, Falck JR, Estabrook W. Cytochrome P450 and arachidonate cascade. FASEB J 1992; 6: 731-6.

9. Fitzpatrick FA and Murphy DA. Cytochrome P450 metabolism of arachidonic acid: formation and biological actions of 'epoxygenase'-derived eicosanoids. Pharmacol Rev 1989; 40: 229-41.

10. McGiff JC. Cytochrome P-450 metabolism of arachidonic acid. Annu Rev Pharmacol Toxicol 1991; 31: 339-69.

11. Zeldin DC, Kobayashi J, Falck JR, Winder BS, Hammock BD, Snapper JR, Capdevila JH. Regio- and enantiofacial selectivity of epoxyeicosatrienoic acid hydration by cytosolic epoxide hydrolase. J Biol Chem 1993; 268: 6402-7.

12. Carrol MA, Schwartzman M, Capdevila J, Falck JR, McGiff JC. Vasoactivity of arachidonic acid epoxides. Eur J Pharmacol 1987; 138: 281-3.

13. Gebremedhin D, Ma Y, Falck JR, Roman RJ, VanRollins M, Harder DR. Mechanism of action of cerebral epoxyeicosatrienoic acids on cerebral arterial smooth muscle. Am J Physiol 1992; 263: 519-29.

14. Zeldin DC, Plitman JD, Kobayashi J, Miller RF, Snapper JR, Falck JR, Szarek JL, Philpot RM, Capdevila JH. The rabbit pulmonary cytochrome $\mathrm{P} 450$ arachidonic acid metabolic pathway: characterization and significance. J Clin Invest 1995; 95: 2150-60.

15. Cashman JR, Hanks D, Weiner RI. Epoxy derivatives of arachidonic acid are potent stimulators of prolactin secretion. Neuroendocrinol 1987; 46: 246-51.

16. Falck JR, Manna S, Moltz J, Chacos N, Capdevila J. Epoxyeicosatrienoic acids stimulate glucagon and insulin release from isolated rat pancreatic islets. Biochem Biophys Res Commun 1983; 114: 743-9.

17. Snyder GD, Capdevila J, Chacos N, Manna S, Falck JR. Action of luteinizing hormone-releasing hormone: Involvement of novel arachidonic acid metabolites. Proc Natl Acad Sci USA 1983; 80: 3504-7.

18. Malcolm KC, Fitzpatrick FA. Epoxyeicosatrienoic acids inhibit $\mathrm{Ca}^{2+}$ entry into platelets stimulated by thapsigargin and thrombin. J Biol Chem 1992; 267: 19854-8.

19. $\mathrm{Hu} \mathrm{S}$, Kim HS. Activation of $\mathrm{K}^{+}$channel in vascular smooth muscles by cytochrome P450 metabolites of arachidonic acid. Eur J Pharmacol 1993; 230: 215-21.

20. Maruyama K, Yoneya S, Miyauchi O, Adachi-Usami E, Nishikawa M. Fish oil (polyunsaturated fatty acid) prevents ischemic-induced injury in the mammalian retina. Exp Eye Res 2002; 74: 671-6.

21. McLennan P, Howe P, Abeywardena MY, Muggli R, Raederstorff D, Mano M, Rayner T, Head R. The cardiovascular protective role of docosahexaenoic acid. Eur J Pharmacol 1996; 300: 83-9.

22. Brash AR. Arachidonic acid as a bioactive molecule. J Clin Invest 2001; 107: 1339-45.

23. Dray A, Perkins M. Bradykinin and inflammatory pain. Trends Neurosci 1993; 16: 99-104.

24. Hoeck WG, Ramesha CS, Chang DJ, Fan N, Heller RA. Cytoplasmic phospholipase $A_{2}$ activity and gene expres- sion are stimulated by tumor necrosis factor: Dexamethasone blocks the induced synthesis. Proc Natl Acad Sci USA 1993; 90: 4475-9.

25. Jupp OJ, Vandenabeele P, MacEwan DJ. Distinct regulation of cytosolic phospholipase $\mathrm{A}_{2}$ phosphorylation, translocation, proteolysis and activation by tumor necrosis factor-receptor subtypes. Biochem J 2003; 374: 45361.

26. Pascual JMS, McKenzie A, Yankaskas JR, Falck JR, Zeldin DC. Epoxygenase metabolites of arachidonic acid affect electrophysiologic properties of rat tracheal epithelial cells. J Pharm Exp Ther 1998; 286: 772-9.

27. Morin C, Sirois M, Echave V, Gomes MM, Rousseau E. Functional effects of 20-HETE on human bronchi: hyperpolarization and relaxation due to BKCa channel activation. Am J Physiol Lung Cell Mol Physiol 2007; 293: L1037-44.

28. Maue RA, Dionne VE. Preparation of isolated mouse olfactory receptor neurons. Pflügers Arch 1987; 409: 244 50.

29. Zhang P, Yang C, Delay RJ. Urine stimulation activates BK channels in couse vomeronasal neurons. J Neurophysiol 2008; 100: 1824-34.

30. Hamill OP, Marty A, Neher E, Sakmann B, Sigworth FJ. Improved patch-clamp techniques for high-resolution current recording from cells and cell-free membrane patches. Pflügers Arch 1981; 391: 85-100.

31. Eto K, Arimura Y, Mizuguchi H, Nishikawa M, Noda M, Ishibashi $\mathrm{H}$. Modulation of ATP-induced inward currents by docosahexaenoic acid and other fatty acids in rat nodose ganglion neurons. J Pharmacol Sci 2006; 102: 34346.

32. Smith ES, Cadiou H, McNaughton PA. Arachidonic acid potentiates acid-sensing ion channels in rat sensory neurons by a direct action. J Neurosci 2007; 145: 686-98.

33. Russell Y, Evans P, Dodd GH. Characterization of the total lipid and fatty acid composition of rat olfactory mucosa. J Lipid Res 1989; 30: 877-84.

34. Meves H. Modulation of ion channels by arachidonic acid. Prog Neurobiol 1994; 43: 175-86.

35. Barrett CF, Liu L, Rittenhouse AR. Arachidonic acid reversibly enhances $\mathrm{N}$-type calcium current at an extracellular site. Am J Physiol Cell Physiol 2001; 280: 1306-18.

36. Vellani V, Reynolds AM, McNaughton PA. Modulation of the synaptic $\mathrm{Ca}^{2+}$ current in salamander photoreceptors by polyunsaturated fatty acids and retinoids. J Physiol (Lond) 2000; 529: 333-44.

37. Hamilton KL, Syme CA, Devor DC. Molecular localization of the inhibitory arachidonic acid binding site to the pore of hIK1. J Biol Chem 2003; 278: 16690-7.

38. Krishtal O. The ASICs: signaling molecules? Modulators? Trends Neurosci 2003; 26: 477-83.

39. Caterina MJ, Schumacher MA, Tominaga M, Rosen TA, Levine JD, Julius D. The capsaicin receptor: a heat-activated ion channel in the pain pathway. Nature 1997; 389: 816-24.

40. Hardie RC. Regulation of TRP channels via lipid second messengers. Annu Rev Physiol 2003; 65: 735-59.

\section{Address for correspondence:}

Andrea Mazzatenta

Department of Neuroscience and Imaging

University Chieti-Pescara 'G. d'Annunzio'

Campus di Madonna delle Piane

Via dei Vestini 31

66100 Chieti

Italy

Phone: +39871 3554044

Fax: + 398713554045

E-mail: a.mazzatenta@unich.it 